\title{
16
}

\section{THE CONSULTATIVE GROUP ON INTERNATIONAL AGRICULTURAL RESEARCH APPROACH TO EVALUATION OF CLIMATE CHANGE, ENVIRONMENT, AND NATURAL RESOURCE MANAGEMENT}

\section{Roberto La Rovere}

\section{Introduction}

The aims of the Consultative Group on International Agricultural Research (CGIAR) are to reduce global poverty and hunger, to improve human health and nutrition, and to enhance ecosystem resilience and the environment through international agricultural research and partnership. CGIAR claims that, had it not existed, world food production would be $4 \%-5 \%$ lower, developing countries would produce $7 \%-8 \%$ less food, world grain prices would be 18\%-21\% higher (adversely affecting poor consumers in particular), cultivated area in the developing countries would be 11-13 million hectares larger (having expanded into fragile forests that harbour a high biodiversity), and per capita food consumption in developing countries would be $5 \%-7 \%$ lower on the average. In a time of global food and ecological crises and of rapid economic, technology, and climate changes, the role of CGIAR is critical.

These crises impose particularly harsh consequences on the approximately 2.1 billion people who live on less than two US dollars a day - three fourths of whom live in rural areas and depend on agriculture. Although investments in agricultural research had seen a declining trend, the 2008 global food crisis brought agriculture back to the fore of the development agenda, which prompted a global revival of funding for agricultural research. Within this context, the role of impact assessment and evaluation to validate the efficiency of funding and the effectiveness of investment has also been growing. This trend has also been driven by the arrival on the global development stage of new and large donors and foundations demanding clear accountability for returns on their investments.

Agricultural research poses particular challenges for evaluation, distinct from evaluation of technical cooperation, investment, and emergency assistance. Research is often very specialized, so its evaluation also demands specialist skills. Impact 
assessment in CGIAR is either associated with impact evaluation or serves as an important input to overall evaluation. Furthermore, the impacts of interventions in agriculture and sustainable development cannot generally be assessed until many years after an intervention ends. The time horizon of impact assessment and evaluation in CGIAR means that it cannot usually be utilized for immediate decisionmaking on current or new programmes.

This chapter outlines the approach to the evaluation of climate change, environment, and natural resource management in the context of the CGIAR. Evaluating the impact of research activities poses specific challenges that differ from evaluating development programmes or normative work. Given the nature of the work of the CGIAR system, it is important to take a systematic and common approach to evaluation that covers the network's various dimensions - including its environmental, social, and economic dimensions. Over the last decade the relative importance, the urgency, and share of CGIAR investments in climate change research in relation to agriculture have also grown dramatically, together with the gearing up of the CGIAR Research Program (CRP) on Climate Change, Agriculture and Food Security (CCAFS) since 2011, and the evaluation of the CCAFS by the CGIARIEA (2016), which forms the basis of the discussion of climate change research and evaluation over the last decade, as well as in this chapter.

\section{CGIAR and its role in climate change, environment, and natural resource management}

The CGIAR, funded by developing and industrialized country governments, foundations, and international and regional organizations, is a global partnership that unites organizations engaged in research for sustainable development. Its complex and unique architecture of partnerships has no equivalent in other international development organizations. Fifteen international research centres carry out CGIAR work in close collaboration with hundreds of national and regional research partners and institutes, civil society organizations, academia, and the private sector. CGIAR objectives include improving food production (by accelerating sustainable increases in productivity and production of healthy food by and for the poor) and creating a better environment (by conserving, enhancing, and using natural resources and biodiversity to improve livelihoods of the poor in response to climate change and other factors).

CGIAR operates within the context of promoting institutional and policy changes that can stimulate agricultural growth and equity to benefit the world's rural poor. A recent restructuring of the CGIAR system added a new outcome, sustainable management of natural resources, to its three traditional system-level, Millennium Development Goal (MDG)-aligned outcomes (those of reducing rural poverty, increasing food security, and improving nutrition and health). The focus on environmental outcomes is now explicit and environmental impact assessments and evaluations of climate change impacts have become an important element of CGIAR's work. 


\section{Environmental, climate change, and natural resource management activities in CGIAR: development and sustainability}

The CGIAR research focus has mainly been on natural resource management. Research on environmental aspects is a more recent but growing focus and research on climate change has progressively taken the central stage over the last two decades. Accordingly, impact assessment and evaluation studies on natural resource management, and the focus on climate change in the last decade, have thus far received more attention than environmental impact assessments.

Natural resource management ${ }^{1}$ research aims to generate outputs that help maintain or improve the natural resource base for agriculture and to mitigate the often negative environmental side effects of agricultural production. In cases in which benefits from natural resource management research are framed in terms of maintained or improved agricultural productivity, farmers are considered the likely adopters of natural resource management technologies such as improved seed irrigation techniques, pest control, and improved management practices. Often, tradeoffs exist between agricultural productivity and conserving natural resources that a society values. In such cases, the incentives for farmers to adopt or not adopt a technology are not always clear. Additional research outputs include influencing policy and creating new institutions to facilitate socially desirable outcomes.

Environment-related work in CGIAR covers different types of agricultural resource use and issues, including land, water, agrochemicals and pesticides, livestock production aspects related to the environment, biodiversity, climate change, forests and deforestation, and greenhouse gas emissions. Environmental impacts in CGIAR refer to public goods associated with ecosystem services that provide inputs into productive processes, such as consumption goods that confer well-being directly (e.g. enjoyment of environmental quality) or indirectly (e.g. drinking water of a given quality), or have non-use values associated with knowing that a particular environmental resource exists (Renkow 2010). Several impact assessments conducted by CGIAR have refrained of measuring environmental impacts due to complexities in assigning monetary values to non-market environmental services.

Natural resource management research impact pathways flow either via adoption of specific outputs by farmers or via institutional innovations and policy influence. In the first case, the outputs (new technologies for managing farm natural resources) are adopted by farmers, leading to either direct (to adopters) or indirect (to nonadopters, labourers, and consumers) impacts that can be either positive or negative and have an economic, social, or environmental nature. In the second case, institutional innovations or policy influence, the outputs consist of engaging with policy makers through dialogue, scientific presentations, briefings, and technical support in creating new institutions for managing natural resources. The resulting outcomes influence policy decision-making, policy changes, and the creation of new institutions contributing to improving natural resource management. Impacts tend to accrue to those ultimately affected by policy changes. CGIAR research on managing soil, fisheries, water, forests, and pests has shown substantial benefits and positive 
internal rates of return on investment. However, much of the impact reported is on a small scale (although there are some exceptions, such as reduced or no-tillage technology that conserves soil and water and reduces carbon emissions).

The environmental and natural resource management and development sides are closely interlinked within the context of farming systems. The environmentpoverty nexus is very strong; people depend on the sustainability of the natural resources and are affected by environmental issues linked to how they manage the natural resource base in their own farming systems. The public goods deriving from CGIAR research are most often technologies and innovations or policy changes that have a direct impact on the farmers' livelihoods and income levels.

Various reviews ${ }^{2}$ reveal that assessing the environmental impacts derived from the use of modern technologies has received limited attention from CGIAR centres. Some progress has been achieved, for example, on quantifying the impacts of research on genetic diversity, soil erosion, and pesticide use (though pesticide studies have focused primarily on human health impacts). More environmental impact assessments are being done at the CGIAR centres, but few results have been published.

The methodology for quantifying productivity impacts of research outputs or outcomes is much more advanced than the methodology for quantifying other types of research impacts (e.g. social, health, equity, and environmental impacts; Djurfeldt et al. 2009). Even the assessment of impacts of CGIAR research investments in natural resource management (where environmental aspects would be expected to be prominent) done by the CGIAR Science Council Secretariat (2006) ${ }^{3}$ and Waibel and Zilberman (2007) includes little quantification of environmental benefits, and the principal focus of assessing these investments remains on agricultural productivity aspects.

As CGIAR is moving upstream from individual projects to clusters of projects (focusing, for example, on a watershed or an agro-ecological zone), this has bearing on evaluation, which must also move beyond project thinking and consider the context of national sustainable development.

CGIAR research in genetic improvements, natural resource management, and policy research has generated a large set of technology, management, and knowledge products (Renkow 2010). These produced a similarly broad set of economic, social, and environmental impacts. Over the past two decades, ex post assessment of these impacts has become increasingly institutionalized, following the growing demand for evidence that CGIAR research investments have generated benefits and good rates of return (Walker et al.2008). Various guideline documents for conducting ex post impact assessments have been followed, both at the CGIAR system and individual research centre level, with a growing emphasis on environmental impacts (Maredia and Pingali 2001; Nelson and Maredia 2001; Shiferaw, Freeman and Swinton, 2005; La Rovere and Dixon 2007; Walker et al. 2008). These documents seek, whenever possible, to build on earlier economic impact assessments, resulting in more comprehensive and integrated types of assessments. In addition, the CGIAR Standing Panel on Impact Assessment serves as a repository of such resources, studies, and methodologies on impact assessment and evaluation (https:// cas.cgiar.org/spia). 


\section{Notable examples of CGIAR studies on natural resource management and environmental impacts}

Little has been done to trace the full chain of outputs, outcomes, and impacts of CGIAR research as it pertains to the natural environment. Impact assessment research in CGIAR initially focused on assessing the impacts of germplasm adoption and crop management research (1970s and 1980s), then shifted to rates of return and benefit distribution assessments (1980s), and research on spillovers and inter-sectoral impacts (1980s and 1990s). In the 1990s, the focus broadened to include significant environmental impact assessment studies (Pingali 2001).

The biggest environmental impact from CGIAR research appears to relate to changes in the total area under agricultural production as a result of widespread adoption of productivity-increasing technologies (see Box 16.1). In this regard, there are two competing types of impact. On the positive side, increases in agricultural productivity in areas used for agriculture may provide a disincentive to clear more land (via reduction in the price of outputs). On the negative side, if the technology raises productivity significantly but only dampens output prices a little, there may be incentives for further clearing of land for agriculture. Other environmental impacts relate to externalities to the agricultural production system, for example, whether adopting CGIAR technologies increases net carbon emissions, reduces biodiversity, or increases the rate at which pollutants are emitted from farming systems. Getting good data that can allow evaluating these impacts is difficult and the relative importance of these factors is uncertain. The use of economic valuation methods, such as contingent valuation or choice modelling, is noted as being able to help identify where such impacts are important (Bennett 2009).

\section{BOX 16.1 ENVIRONMENTAL CONSIDERATIONS AROUND THE GREEN REVOLUTION}

One of CGIAR's greatest - if not the greatest - success stories is the green revolution in South Asia, catalysed by personalities such as the 1970 Nobel Peace Prize Winner Dr. Norman Borlaug. From 1960 to 2000, international agricultural research centres, together with national research programmes, contributed to developing modern varieties for many crops. These varieties have contributed to large increases in crop production. Productivity gains were, however, uneven across crops and regions. Consumers generally benefitted from declines in food prices. Farmers benefitted only where cost reductions exceeded price reductions (Evenson and Gollin 2003). The green revolution helped to pull the South Asia region back from the edge of an abyss of famine, led to regional food surpluses within two decades, lifted millions of people out of poverty, made crucial contributions to economic growth, and saved large areas of forest, wetlands and other fragile lands from being converted to farmland. The research behind the 
green revolution achieved the objectives of the time and yielded high rates of economic return. However, Hazell (2008) points out that new problems and challenges arose that required significant evolution of the research and development system and its research priorities. Poverty and malnutrition were not eliminated and, although poverty shares fell, the number of poor people remained high. The study by Evenson and Gollin (2003) neglected the environmental impacts and the environmental costs (e.g. of pesticide use) that have been largely identified in subsequent studies.

In fact, the green revolution introduced new environmental problems of its own, especially those related to poor management of irrigation water, fertilizers, and pesticides. Doubts have increasingly arisen regarding the sustainability of intensively farmed systems and regarding off-site externalities such as water pollution, siltation of waterways and loss of biodiversity have imposed wider social costs. In this evolving context, research and development priorities have changed from a narrow focus on productivity of food grains to a need to focus on natural resource management and sustainability issues. The results of this changing research agenda are mixed, but considerably more research has focused on South Asia's agriculturally related environmental problems.

In green revolution areas, the best yields and environmental impacts have been obtained from research on more efficient use of fertilizers, water, and integrated pest management practices. For example, the latter appeared to save on pesticide costs, reducing workers' exposure to harmful pesticides and protecting biodiversity. No-tillage and greater incorporation of organic matter into intensively farmed soils have also proven beneficial.

The evidence is less clear about the benefits of organic farming or systems of rice intensification. Research on these topics generated favourable results, but the potential benefits have been constrained by adoption levels that are far too small in relation to the scale of the environmental problems to be solved. Major reasons for poor adoption include the higher labour requirements of many improved management practices, the high levels of knowledge required by farmers, water and fertilizer subsidies in many South Asian countries, and the externality of some environmental issues. These are typical issues emanating from research that need complementary changes in policies and local institutions to be effective.

Following the green revolution model, several examples of research on watershed development and associated soil and water management issues have contributed to successful watershed development programmes in South Asia that integrated environmental impacts. These have been shown to increase agricultural productivity, reduce soil erosion, and improve groundwater levels. In the late 1990s, another CGIAR initiative explored the extent of land savings that were attributable to large productivity increases that followed widespread dissemination of improved varieties (Renkow 2010; Stevenson et al. 2010). 
Had CGIAR crop genetic improvement work not taken place, an additional 20-25 million hectares of land in developing countries would have been needed at the beginning of the 21st century to produce the same amount of cereal output, with implications for larger carbon emissions, biodiversity loss, and water use. A 2010 review examined the impact on global land-use change of crop germplasm improvements in major mandate crops of CGIAR (e.g. rice, wheat, maize, and several others) between 1965 and 2004 (Stevenson et al. 2010). The study, conducted with the aid of a global multi-commodity, multiregional computable general equilibrium model linked to a global spatially explicit database on land use, supports Borlaug's hypothesis that increases in cereal yields as a result of widespread adoption of green revolution technologies that have saved natural ecosystems from being converted to agriculture (although the results suggest that this effect is of a much smaller magnitude than hypothesized). The total agricultural area in 2004 would have been between 18 and 27 million hectares larger (of which 12-18 million hectares would have been in developing countries) if the world had not benefitted from crop germplasm improvements since 1965.

\section{CGIAR approaches to evaluation and impact assessment}

The CGIAR mandate initially focused on improving crop genetics, but has since expanded to include a range of subjects and activities extending the scope of research and impact assessment to natural resource management and environmental impacts (Djurfeldt et al. 2009) and climate change impacts increasingly more chiefly since the early 2000s. In methodological terms, this broadening of responsibility posed a number of challenges. Although issues in crop genetic improvement may be evaluated with techniques that seem to offer a high level of credibility (e.g. econometrics), social and policy-oriented research often require methods that are less prone to generalization and different from the standards of traditional science (e.g. qualitative approaches). Whereas the CGIAR centres have generally measured poverty by using income and consumption data, current impact evaluations include the concept of sustainable livelihoods. Such assessments seek a broader and more holistic understanding of poverty, taking into account a variety of factors that influence or impinge on people's capacity to address their vulnerability and poverty (e.g. access to land and water, social relationships, physical safety, and personal strategies to achieve context-specific and individual livelihood goals). Given the character of these questions, a combination of qualitative and quantitative methods is the most appropriate. This makes it possible to identify factors such as causal relationships, general trends, and adoption rates while also considering the multidimensional nature of poverty and the indirect consequences of agricultural research.

Problems arise in trying to scale up to larger geographical aggregation levels (particularly at the country level, which, for CGIAR, is not a level of intended 
impact). Although individual CGIAR centres may have an interest in impact assessment at a lower (farmer or intermediate) scale in order to evaluate specific research products or programmes, there is a clear imperative at the CGIAR system level to demonstrate large-scale impacts. However, the CGIAR level of impact and impact evaluation is either sub-national (e.g. community, watershed, regional) or supranational in multi-centre research programmes designed to address global or regional issues that could solve environment-related problems (e.g. water scarcity and climate change).

In addition to the issue of scale, the choice of appropriate research tools (qualitative and/or quantitative methods), addressing issues such as attribution, the existence of baseline data, the design of counterfactuals, and environmental valuation are considered as critical to adequately and meaningfully conduct an environmental impact assessment. Some of these issues are elaborated on in the following sections.

\section{Qualitative and quantitative methods}

The choice between qualitative and survey-based (quantitative) statistical approaches involves trade-offs; combining both is generally recommended. In the assessment of sustainable livelihoods, the combination of qualitative and quantitative methods needs to be comprehensive and carefully planned (La Rovere and Dixon 2007; Walker et al. 2008). Combining approaches makes it possible to estimate the indirect consequences of agricultural research and to establish a detailed and contextual assessment while simultaneously identifying the quantitative patterns of impact. Most recent guidelines recommend CGIAR use combined research impact tools.

\section{Baseline data}

A weakness in many studies is the absence of baseline data. This is evident in natural resource management cases, which often rely on the "best" available data and indirect indicators. One explanation for this is that impact assessments were not planned for when projects were designed and launched. To mitigate this, an obvious recommendation is proper planning for evaluation processes in the initial phase of a project. Recently, donors have provided substantial funding to CGIAR, which has enabled the establishment of extensive baseline databases that will permit rigorous tracking of projects or programme impacts over time.

\section{Counterfactuals}

In the absence of baseline data, impact assessment is methodologically challenging, not only due to poor benchmarks but also because baseline information is necessary to establish counterfactuals. The history of CGIAR ex post impact assessments at the project and programme levels is significant, but the use of proper before and 
after counterfactuals (as well as with and without counterfactuals) is less frequent due to the noted scarcity - until recently - of properly designed baselines and comparison groups.

\section{Valuation methods}

The majority of impact assessments and evaluations have neglected to incorporate non-market environmental impacts (impacts that do not translate into monetary costs) because estimating research impacts outside market effects is complex (Bennett 2009). With evaluations being established largely within the conceptual rigour of traditional cost-benefit analysis, the inclusion of non-marketed effects requires the estimation of benefits and costs in monetary terms. Hence, for evaluations to include non-market benefits and costs requires not only the already challenging processes of forecasting the impacts of research outputs on various goods and services (marketed and non-marketed) but also the estimation of society's values for all the forecast impacts.

CGIAR's evaluations mostly draw attention to the omission of environmental impacts in their scope. For example, Hazell (2008: XV in a study of agricultural research in South Asia concludes "there are few impact studies from South Asia that estimate a return to a research investment corrected for environmental benefits and costs". He also points to the use of indicators as a means of ranking research investments in terms of both their environmental and poverty impacts. There is also no real consensus as to which indicators should be used. Without a consensus, the use of indicators remains arbitrary and limited. Empirical studies are recommended to link research investments to environmental outcomes in order to assess past investments and design more effective research initiatives.

The 2011 Independent Science and Partnership Council book on CGIAR sheds light on the state-of-the-art methodological progress on valuation methods (choice modelling and contingent valuation) and ongoing work on measurement, modelling, and data collection for environmental impact assessment of agricultural research.

\section{The rise of climate change investments and evaluation}

Since 2011, the growing research efforts on climate change impacts on agriculture, until then scattered in individual research activities of the various CGIAR centres and of the Climate Change Challenge Program, converged through the establishment of the Research Program on CCAFS. CCAFS built on the earlier CGIAR Challenge Program on Climate Change to bring together earlier centrebased research efforts on climate-related agricultural matters. CCAFS addresses the challenges that global warming poses on food security and agricultural producers, production systems, policies, and institutions ${ }^{4}$ (from the CGIAR-IEA, 2016). One key concept for implementing CCAFS activities, which received increasing attention over the past decade, is climate-smart agriculture (CSA, see Box 16.2). 


\section{BOX 16.2 CLIMATE-SMART AGRICULTURE}

CSA is a conceptual approach developed to advocate for changes in how agriculture is practised and agricultural development is understood with respect to climate change impacts. CSA involves the optimization of the objectives of: sustainably increasing agricultural productivity to support equitable increases in farm incomes, and better food security; adapting and building resilience of agricultural and food security systems to climate change at multiple levels; and reducing greenhouse gas emissions from agriculture (including crops, livestock, and fisheries). The term CSA was coined by FAO for the 2010 Hague Conference on Food Security, Agriculture and Climate Change, ${ }^{5}$ CCAFS being an early partner in developing the CSA. The approach asserts that addressing emerging climate risks while reducing greenhouse gas emissions requires new technologies, policies, institutions, and investment and that context-specific interventions are required. CSA responds to the challenges of climate change to optimize and balance the objectives of productivity, adaptation, and mitigation. CCAFS implements a large proportion of its work on CSA through "climate-smart villages" where CSA interventions are tested with partners, while seeking policy influence and direct engagement with governments.

Since CCAFS started, the CGIAR adopted a new Strategy and Results Framework (SRF) setting common goals for the CGIAR in terms of development impact, strategic objectives and results, and Intermediate Development Outcomes for the CRP portfolio and for individual CRPs. CRPs were instructed to articulate impact pathways and Theories of Change (ToC) and develop targets and achievement indicators. In 2015, CCAFS proposed a second phase for 2017-2022 that included CSA in order to meet the global cross-cutting needs of climate change with comparative advantage for the CGIAR, focusing on the adaptation and mitigation options in agriculture to contribute to resilience to climate shocks. The SRF commits the CGIAR to devote nearly two thirds of its research to such issues. With annual budgets around USD 60-70 million, CCAFS is one of the largest CRPs, with expenditures among the highest in the Research Theme on Adaptation, as well as relatively even among the other Research Themes.

\section{Global context in climate change research and policy}

At the 21st Paris Conference of the Parties (COP) in 2015, agreement was reached on Sustainable Development Goals, recognizing that UNFCCC remains paramount regarding climate change issues and setting high level ambitions for adaptation and mitigation. The agreement structures the activities on mitigation around the (voluntary) intended nationally determined contributions (INDCs) and recognizes the 
need for adaptation. While research on the role of agriculture in mitigating climate change initially concentrated on potential in developed countries, this changed in the past decade. The impacts of climate change on agriculture and food security, especially in developing countries, and the role of agriculture in increasing resilience, became increasingly recognized topics of research. In the Intergovernmental Panel on Climate Change (IPCC) reports, agriculture is treated as a cross-cutting issue related to food security and food production, human health, and adaptation options. With CCAFS, agriculture started being included as a mitigation option for developing countries in the Nationally Appropriate Mitigation Actions (NAMAs), and the CRP aimed at exploring synergies and trade-offs between mitigation and adaptation. These aspects have been gaining relevance and are now recognized as central for addressing climate change and contributing to achieving several Sustainable Development Goals.

\section{Evaluation of climate change and CCAFS in the new setting of the CGIAR}

The Independent Evaluation Arrangement (IEA) of the CGIAR evaluated in 2016 the CRP on CCAFS, to improve the CRP's performance and identify ways to maximize the contributions that CCAFS can make to future food security in the context of climate change, by informing decision-making and planning by the CRP management, CRP sponsors, partners, and other stakeholders on aspects of program performance and options for the future of the Program. Performance was evaluated to assess the quality of science by assessing a random sample of journal articles by CCAFS, and the Program's efficiency and organizational performance ${ }^{6}$ at global Program, Flagship and Regional Program levels. The evaluation of the research contribution also included bibliometric analysis and $\mathrm{H}$-index analysis of senior researchers, contributing to the CCAFS' comparative advantage and quality of science. CCAFS engages in generating international public goods (IPGs) as global knowledge producer, as a provider of products and services, and as a repository of institutional capacities for international research on climate change related to agriculture and food security. CCAFS outputs with clear applicability across national borders and high IPG potential include weather index-based insurance systems, climate information services (CIS), Web-x Evaluation of the CRP on CCAFS web-based Climate Portal, climate analogues and tools for measuring mitigation benefits in agriculture. With the growing effects of climate change on global development agendas, the CGIAR benefitted from CCAFS integrating research across CGIAR centres and strengthening its presence in policy dialogues. While operating at the global level, CCAFS grounded its research activities in national activities and institutions.

CGIAR-IEA (2016) evaluation examined CCAFS research since its launch, irrespective of funding sources. The evaluation covered investigative activities by CCAFS and partners. The evaluation considered research for development approaches, whereby CCAFS convenes and facilitates investigative action by partners 
and studies them. The evaluation used both summative and formative dimensions to the case study assessments. Since many projects originated in work started before the CCAFS Challenge Program, some work was assessed in summative ways, and current and proposed future work in formative ways. The governance and financial management of CCAFS was not covered in depth by the IEA as it had been examined by earlier reviews.

Other elements of CGIAR evaluation as well as of planning, monitoring, and learning work of the CGIAR have been subject to studies or assessments. Among these, CCAFS's Monitoring, Learning and Evaluation (ML\&E) system ${ }^{7}$ provides mechanisms to ensure the quantitative and qualitative monitoring, building on a set of modules in an online ML\&E Support Pack. The ML\&E strategy was implemented during the second phase of the CCAFS program until 2025 by using a results-based management (RBM) approach and supports an evaluation culture of reflective learning, experimentation, and adaptive management. Also, by integrating ML\&E mechanism through CCAFS in projects, it supports outcomes that include changes in practices, skills, and behaviour of researchers, policy makers, extension services, farmers, and other user groups. In terms of planning and monitoring outcomes and learning, Schuetz et al. (2017) provide insights on the approach to theory of change, impact pathways, and results-based management monitoring, evaluation, and learning system. It describes how the CGIAR theory of change ${ }^{8}$ can be used to achieve impacts that balance the need to generate knowledge in agricultural research with the priorities of users and beneficiaries of the CGIAR.

\section{Conclusion}

CGIAR has a long history of impact assessment and evaluation, which in the last two decades has increasingly covered aspects of natural resource management and, more recently and explicitly, environmental and climate change impacts. However, a scarcity of methods to assess environmental impacts persists. This, rather than capacity, limits the proper assessment of such impacts. The conventional approach of focusing on quantitative tools and on attribution of impacts has evolved, as the use of qualitative approaches and contribution analysis has gained ground. Yet pressure arising from multiple sources (donors and evaluation fora) towards the perceived higher rigour achievable through quantitative approaches and attribution is being reapplied on impact assessment, and evaluation practitioners. This demand is stimulated (or often enforced) by major donors insisting that a quantitative approach is the only credible one.

These influential donors are almost always located in the same places (i.e. countries, cities, intellectual circles) as the academic institutions where such tools are being promoted. It is difficult for evaluation practitioners operating in the field close to the issues being evaluated but far from the main intellectual and funding hubs - to resist these demands and maintain the otherwise well-accepted practice of a wise, situation-driven choice of mixed methods. 
CGIAR covers global-scale issues, although its research outputs and impacts tend to be location specific. It works at two levels of impact, specifically the sub-national and supranational (agro-ecology or watershed), but has recently expanded to operating in more integrated ways with donors and governments at the country level. This is done to facilitate dissemination and uptake of research outputs by a country's public and private sectors.

Scarcity of research resources has only recently been offset by the availability of funds driven by a sense of urgency for CGIAR's work to address food crises worldwide. As a result, ex ante impact assessment studies to inform resource allocation and justify investments have been gaining ground, together with the explicit identification of impact pathways on livelihoods. The CGIAR's impact assessments and evaluations have been typically ex post ones, focusing on impacts beyond the outcomes. This is in line with the nature of CGIAR's mandate on public goods, which refers to achieving both direct and indirect impacts of research outputs with a longer-term timeframe for influencing change in people's lives.

In the future, a more systematic common approach to impact assessment and evaluation that considers jointly the impacts across all dimensions - economic, social, and environmental - is suggested for CGIAR (Renkow 2010). Achieving this is constrained by the fact that, while the economic impacts are more readily measured in quantitative, monetary terms than social or environmental impacts, environmental impacts typically arise to a large degree from changes in flows of goods and services for which there is often no market and are thus less tangible.

The concentration of CGIAR's evaluation policy on principles and on best international evaluation practice is inspired by policies by a number of international organizations' governing bodies as well as by several international financing institutions. The availability of the UN Evaluation Group (UNEG) guidelines for development evaluation can become very useful to the CGIAR towards a more coherent, uniform evaluation practice, and hopefully can halt the proliferation of centre- or issue-specific guidelines. This more unified practice is expected to more systematically include the relevance, effectiveness, impact, and long-term sustainability criteria. For example, CGIAR criteria for deciding on the coverage and frequency of evaluations, including its usefulness for accountability, decision-making, learning, improvement, efficiency, and avoidance of duplication are well in line with those of the United Nations (UN). By heading in a harmonized direction, the evaluation practice in CGIAR can help focus on the main cross-cutting issues and on the big picture, especially at a time when CGIAR centres are converging into a larger consortium that resembles (in terms of modalities and aims) the UN system itself. This new consortium is aimed at coherence, alignment, and a collective strategic effort by the various research centres. This will also respond to the Paris Declaration and Accra Accords through the alignment of financing by international donors for international agricultural research.

The IEA had since 2012 central evaluation functions, with characteristics of independence, and separate lines of responsibility and responsiveness to all parties 
in the consortium. The IEA evaluation of climate change impacts of the CGIAR (as part of the CCAFS programme) is provided as an example of a comprehensive assessment of the CGIAR increasing research efforts, particularly over the last decade, on climate change matters.

\section{Notes}

1 See, for example, https://www.cgiar.org/research/publication/managing-naturalresources-sustainable-production-systems-research-agenda-crossroads/.

2 For example, see Renkow (2010).

3 This assessment reviewed the impacts of past investments in natural resource management research on land, water, and biodiversity resources management in CGIAR. It responded to concerns on the shortage of credible evidence that natural resource management research does contribute to realizing the CGIAR mission on poverty, food security, and the environment. The review covered a set of geographical regions (Asia, North Africa, sub-Saharan Africa, global) including macro- (related to policy and institutions) and micro-oriented (commodities and farm-level technology) research projects. Most research started 20-25 years ago, meaning that there was a good interval between research and evaluation. In the policy cases, it was only possible to identify - not quantify - impacts. Although the returns did not reach levels often achieved for much of the CGIAR's crop breeding research, returns of natural resource management research projects were calculated without estimating the positive spillover environmental benefits, which may outstrip the benefits deriving from crop germplasm improvement research.

4 CCAFS goal is to "promote a food secure world through provision of science-based efforts that support sustainable agriculture, enhance livelihoods, adapt to climate change, conserve natural resources and environmental services". It comprises four Flagship Projects: Climate-smart agricultural practices, climate information services and climateinformed safety nets, low-emissions agricultural development, policies and institutions for climate-resilient food systems.

5 http://www.fao.org/climate-smart-agriculture; https://ccafs.cgiar.org/climate-smartagriculture-0\#.XjVAb2hKjD4.

6 Including aspects relating to resource use; priority setting and planning; reviewing and reporting; learning; internal and external communication and relationships; and stakeholder involvement.

7 https://ccafs.cgiar.org/planning-monitoring-learning-and-evaluation\#.XhzljFVKjIV.

8 The Theory of Change of CCAFS emphasizes strategic partnerships, capacity building, open access data, communication, real time monitoring and evaluation, and gender and social inclusion.

\section{References}

Bennett, J., 'Advancing ex-post impact assessment of environmental and social impacts of CGIAR', Independent Science and Partnership Council, Rome, CGIAR Standing Panel on Impact Assessment, 2009.

CGIAR, Standing Panel on Impact Assessment (SPIA), 'Natural Resources Management Research Impacts: Evidence from the CGIAR': Rome, Science Council Secretariat, 2006.

CGIAR-IEA (2016), Evaluation of the CGIAR Research Program on Climate Change, Agriculture and Food Security (CCAFS). Rome, Italy, Independent Evaluation Arrangement (IEA) of the CGIAR 
Djurfeldt, G., T. Fagerström and A. Fredholm, 'Research Design in Assessing Social and Environmental Impact of Agricultural Research', Standing Panel on Impact Assessment, Rome, 2009.

Evenson, R. and D. Gollin, 'Assessing the impact of the Green Revolution, 1960 to 2000', Science 300: 758, 2003.

Hazell, P.B.R., 'An Assessment of the Impact of Agricultural Research in South Asia Since the Green Revolution', FAO, Rome, 2008.

Independent Science and Partnership Council, 'Measuring the Environmental Impacts of Agricultural Research:Theory and Applications to CGIAR Research', CGIAR, Rome, 2011.

La Rovere, R. and J. Dixon, 'Operational Guidelines for Assessing Impact of Agricultural Research on Livelihoods: Good Practices from CIMMYT', Working document, International Maize and Wheat Improvement Center (CIMMYT), Texcoco, Mexico, 2007.

Maredia, M. and P. Pingali, 'Environmental Impacts of Productivity-Enhancing Crop Research: A Critical Review', Technical Advisory Committee (TAC), Standing Panel on Impact Assessment (SPIA), Rome, 2001.

Nelson, M. and M. Maredia, Environmental Impacts of the CGIAR: An Assessment, TAC SPIA, Rome, 2001.

Pingali, P., Milestones in Impact Assessment Research in the CGIAR, 1970-1999: With An Annotated Bibliography of Impact Assessment Studies Conducted in the CGIAR, 1970-1999, by Matthew P. Feldmann, TAC SPIA, Mexico, 2001.

Renkow, M., 'Assessing environmental impacts of CGIAR research: Toward an analytical framework', Working paper, SPIA, Rome, 2010.

Schuetz T, Förch W, Thornton P, Vasileiou I. 2017. Pathway to impact: Supporting and evaluating enabling environments for research for development. In Evaluating climate change action for sustainable development. Uitto JI, Puri J, van den Berg RD (eds.). Chapter 4, pp. 53-79. Springer, Cham, Switzerland.

Shiferaw, B., H. Freeman and S. Swinton, eds., Natural Resources Management in Agriculture: Methods for Assessing Economic and Environmental Impacts, CABI Publishing, 2005.

Stevenson, J., D. Byerlee, N.Villoria, T. Kelley and M. Maredia, 'Agricultural Technology, Global Land Use and Deforestation: A Review', CGIAR, Rome, 2011.

Waibel, H. and D. Zilberman, International Research on Natural Resource Management: Advances in Impact Assessment, Studies from the CGIAR, CAB International, Oxfordshire UK, 2007.

Walker, T. et al., 'Strategic guidance for ex-post impact assessment of agricultural research', Report for the SPIA, CGIAR Science Council Secretariat, Rome, 2008. 